\title{
Development of processing technology and mathematical model of modification of magnesite raw material
}

\author{
MICHAL LEŠKO ${ }^{1}$, MILAN BÚGEL ${ }^{2}$, TOMÁŠ BAKALÁR ${ }^{3}$ \\ ${ }^{1}$ Prof. Ing. Michal Leško, PhD, ${ }^{2}$ Assoc.Prof. Ing. Milan Búgel, PhD, ${ }^{3}$ Ing. Tomáš Bakalár, Technical \\ University of Košice, Faculty of Mining, Ecology, Process Control and Geotechnologies, Department \\ of Mineralurgy and Environmental Technologies, Park Komenského 19, 04200 Košice
}

(Received November 2002 Accepted December 2002)

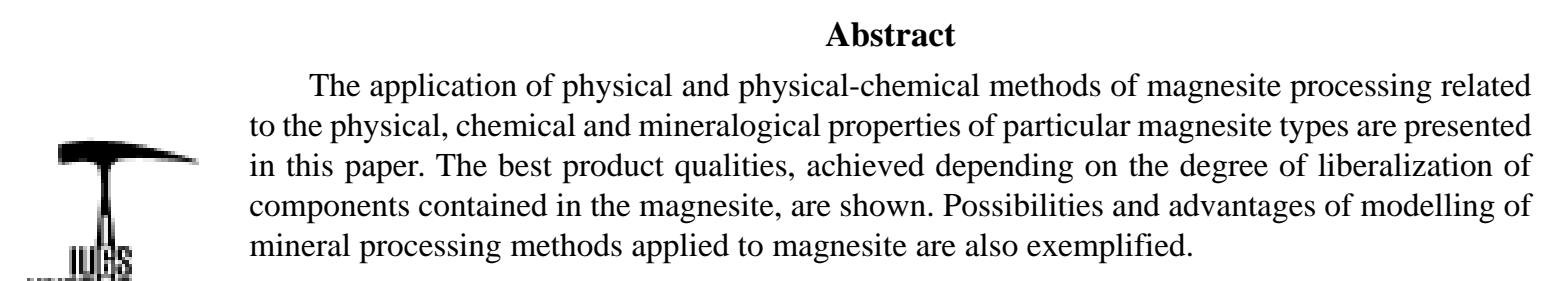

Key words: magnesite, magnesite modification, sinter, mathematical model

IGCP 443

\section{Introduction}

Intensification of steel production on the turn of $19^{\text {th }}$ and $20^{\text {th }}$ centuries was caused by application of basic building materials in the lining of blast furnaces. It is also joined with exploitation of Slovak magnesite deposits. However, the utilization of magnesite is much wider in various branches of industry: e.g. caustic magnesite in agriculture, chemical industry, metallurgy, rubbermaking, petrochemical, building and other industries. Magnesite is used in production of metallic magnesium, in chemical industry and in the production of various chemical compounds.

In contribution a mathematical model of modification of magnesite raw material is described. The technique will be applied to the conditions of a factory in Košice consisting of finishinga plat of raw materials and magnesite sinters. The mathematical model of modification of magnesite raw material is made out of a technological scheme. The model can be used for predicting the results of modification, evaluation of modification efficiency, technical and economical audit of magnesite modification and projecting of technological units or particular technological operations. Matrix models of operations present mathematical models of partial operations.

\section{Progress of magnesite processing technology}

Recent physical methods of magnesite modification have been used in Slovakia since half of $20^{\text {th }}$ century. At the beginning the quality of raw material was ensured by selective mining, later by manual sorting on conveyor belts. In this way the batch was supplied in pit furnaces (PF) that were used from the beginning of magnesite burning - Jelšava (Jarco \& Skála 1986) in Slovakia.

The growth of steel production caused the need to build new steel factories. For these technological units the fireproof brickwork was made from quality magnesite sinters made from quality raw materials, which could be only assured by building finishing plants.

Cylindrical furnaces were used from the beginning of $20^{\text {th }}$ century (1903 - Radenthein Austria, 1909- 1910 - Haèava), but their expansion was related to intensive industrialisation after 1950.

Cylindrical furnaces (a total of 8), except for 7 pit furnaces were put into operation.

It was possible to joint the growing amount of mined raw material, to the growing proportion of mechanical mining and also to the growing demand of produced sinter by:

- introducing of the modification of magnesite raw material, 
- modification of the magnesite sinters,

- chemical production of $\mathrm{MgO}$.

\section{Modification of mined magnesite raw material}

For the reasons mentioned above a dense-suspension finishing plant of magnesite - PIC system was put into operation in Košice. The concentrates of the finishing plant at quality of KI a KII, of fraction 10(15)-60 mm were burned in CF 1-4 to brick and steel sinter. The same technological system was applied in the factory in Lubeník. There was installed a low-volume densesuspension TESCA system in the factory in Jelšava, which was later replaced by PIC system, but of higher capacity than the one in Košice.

The additional phases of effective use of mined raw material were:

- introduction of modification of raw material fraction 1-10(15) $\mathrm{mm}$ in cyclone,

- use of fly, which arise at burning of raw material in cylindrical furnaces, processing of fly was handled in the first stage by pelletizing, but because of low bulk weight of burned magnesite sinters this method was not applied.

The second technology that was already applied to fly processing is briquetting.

When processing magnesite the problem of use of fine-grained fractions $0-1(5) \mathrm{mm}$ of mined magnesite raw material still remained. For this reason a flotation line with a basic and two purification operations without any reviser operation was put into test run. According to the results reached, the construction of flotation was realized in Košice (Jarco \& Skála 1986). A similar tendency was also observed in Jelšava, where the corresponding technologies were to be realized after 1990 (Leško 1996; Šotek et al. 1986).

Such technological solution also related to the processing of fly - briquetting, because burning flotation concentrate was realized by burning caustic magnesite that was being grinded, briquetted and burned in cylindrical furnaces and later in PF. Recovery of $\mathrm{MgO}$ was increased to $83 \%$ by the mentioned method and introducing calcination. The parameter of recovery approximates to its limit value that is, at the same time, the limit of quality of produced sinters, using the physical methods of modification. The quality of the concentrate achieved by modification of raw material is qualified according to the content of harmful substances: $\mathrm{CaO}$ and $\mathrm{SiO}_{2}$. Recently the following parameters of harmful substances achieved by modification were:

$\begin{array}{lrll}\text { concentrate (dense suspension) } & 2.2 / 2.7 & \% \mathrm{CaO}+\mathrm{SiO}_{2} \\ \text { concentrate in cyclone } & 2.2 / 3.2 & \% \mathrm{CaO}+\mathrm{SiO}_{2} \\ \text { flotation concentrate } & 1.3 & \% \mathrm{CaO}+\mathrm{SiO}_{2}\end{array}$

It was not possible to achieve further reduction of content of harmful substances using physical methods of modification.

\section{Modification of magnesite sinters}

Another way to increase the quality of magnesite products is modification of magnesite sinters. Magnetic separation of sinters has not found an equivalent substitute for almost 100 years. It was not possible to modify the magnesite sinters of silicate raw material from cylindrical furnaces by magnetic separation that is the reason, why this technology was not used for modification of sinters. Sinters from $\mathrm{PF}$ and sinters from $\mathrm{CF}$ that acquired burned calcic raw materials that have a higher content of $\mathrm{Fe}$, were modified by magnetic separation.

\section{Chemical production of $\mathrm{MgO}$}

Further increase of fireproof materials quality is connected to the use of pure materials: oxides, especially $\mathrm{MgO}$ in combination with $\mathrm{Al}_{2} \mathrm{O}_{3}$ and $\mathrm{Cr}_{2} \mathrm{O}_{3}$. These requirements can only be met by application of chemical technologies. Such technology is applied to the production of iron-free $\mathrm{MgO}$ (Leško 1998).

The positive development of magnesite technologies was interrupted by the dividing of the old organization into separate units after 1992 that in market, financially burdened by previous capital construction, had problems to pass successfully. This way the continuity of effective use of mined raw material and the synergism of development of magnesite industry was lost in Slovakia.

\section{Technology of production of magnesite sinters}

The production of magnesite fireproof materials is characterized by several specifics and it is divided into following technological parts:

- modification of mined magnesite, 
- thermic processing of magnesite concentrates,

- modification of magnesite sinters,

- production of magnesite fireproof materials.

The listed technological units are presented by technological operations:

- grinding and milling,

- briquetting and pressing of fittings,

- phase separations:

sorting on sieves,

hydraulic sorting,

sorting in dense suspensions,

flotation sorting,

magnetic sorting,

- interphase sorting:

unwatering

dust $\}$ sedimentation, filtration

- thermal operations:

burning of magnesite sinters,

burning of magnesite building materials,

- chemical operations:

production of pure $\mathrm{MgO}$,

production of chemically fixed building materials and fireproof concretes.

Complex of these operations in mutual connection creates a technological scheme: the operations are realized in corresponding machines and equipments. The result of the technological method of modification is determined by:

- properties of raw material,

- structure of technological scheme,

- control level of the technological process.

The content of the contribution is not the analysis of the level of control of the technological process, water and sludge management, circulation of operating and diluted suspension, thermic processes either the processes of briquetting and pressing.

The properties of raw material are always qualified according to that characteristic that is used in the technological operation and that reflects the performance of the raw material in this operation.

\section{Properties of the raw material}

The properties of raw material are qualified following the contents of harmful materials $\left(\mathrm{Fe}_{2} \mathrm{O}_{3}, \mathrm{CaO}\right.$, $\mathrm{SiO}_{2}$ etc.), the way to outgrow the useful and harmful compounds are given by the genesis of the deposit. From the technological position for sorting operations they are characterised:

- by the function of separation of mass according to the separation characteristic $-\gamma(k)$. The symbol $k$ represents the characteristics that are used at separation. For example at sorting on sieves it is the size of particle $-d$, at sorting in dense suspensions it is the density $-\rho$ etc.,

- by the function of separation of useful and harmful compounds according to the separation characteristic $-\beta(k)$.

If there are more arguments, functions with two or three arguments can be created.

Functions representing the properties of raw materials are detected by technological analysis and they are presented:

- in numerical form - tables,

- in graphical form - granularity curves, modifiability curves,

- in analytical form.

The structure of the technological scheme determines the separation characteristic of the object and it is determined by:

- characteristics of elements creating the object machines and equipments,

- relations between the elements of the object mutual connection of machines and equipments.

The characteristics of each machine used are described by the separation capability that can be presented:

- in the worst case by technological parameter, e.g. partial weight yield of particular product and partial recovery of the studied compound,

- distribution function - e.g. Tromp's curve in numerical or analytical form $\varepsilon(k)$. 
In more complicated schemes the theory of transmissive functions can be used for this purpose (Leško 1998).

\section{Mathematical model of magnesite processing}

Various modification processes are used when processing magnesite - from grinding to briquetting with consequent thermal operations - scheme in Fig.1. We will follow this scheme to discuss this problem.

\section{Mathematical model of modification of magnesite raw material}

Vectorial expression will be used for the mathematical description of the technological scheme of modification of magnesite because it enables characterization of technological relations respecting the structure of technological process. The technological scheme of modification is shown in Fig.2. Mathematical models of particular operations were presented before, e.g. models of sorting and grinding (Leško 1996; Lynch 1981), models of sorting (Leško 1998; Leško \& Zeleòák 1994). The characteristics of particular components of mathematical models will be described in particular operations. Vectorial expression is characterised by brief expression because each vectorial expression represents as many linear equations as fractions or components we study. The following expression describes the flux of material - solid state - through a technological line. In similar way it is possible to create a model of flow of water, sludge, operating and diluted suspension.

Symbols used:

$\boldsymbol{Q}_{\boldsymbol{i}}$ - vector representing material flux $i$ in the system - column format $(K \mathrm{x} 1)$,

$i=0,1, \ldots, I$, where $I-$ number of material fluxes

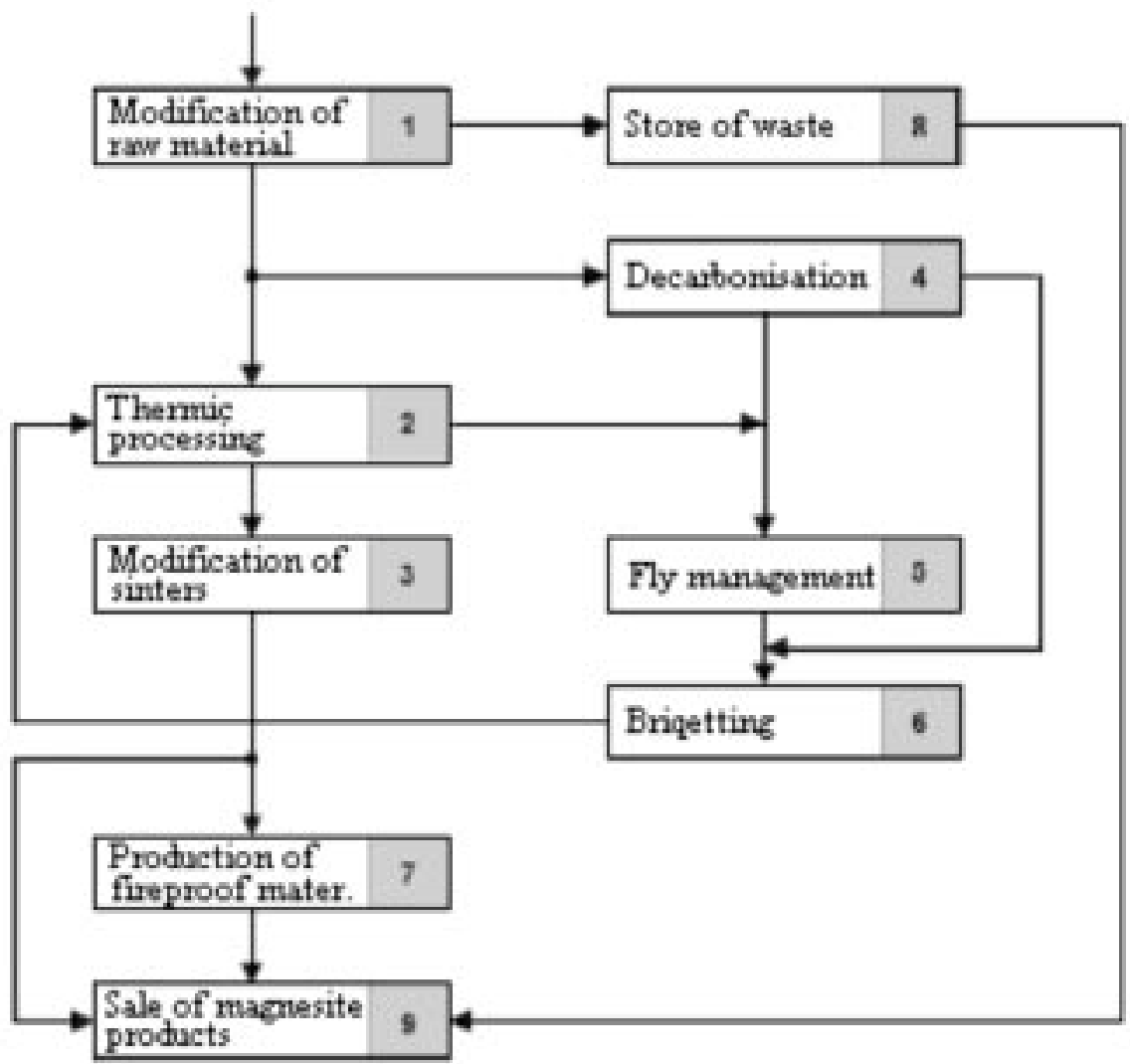

Fig. 1. Scheme of magnesite processing 


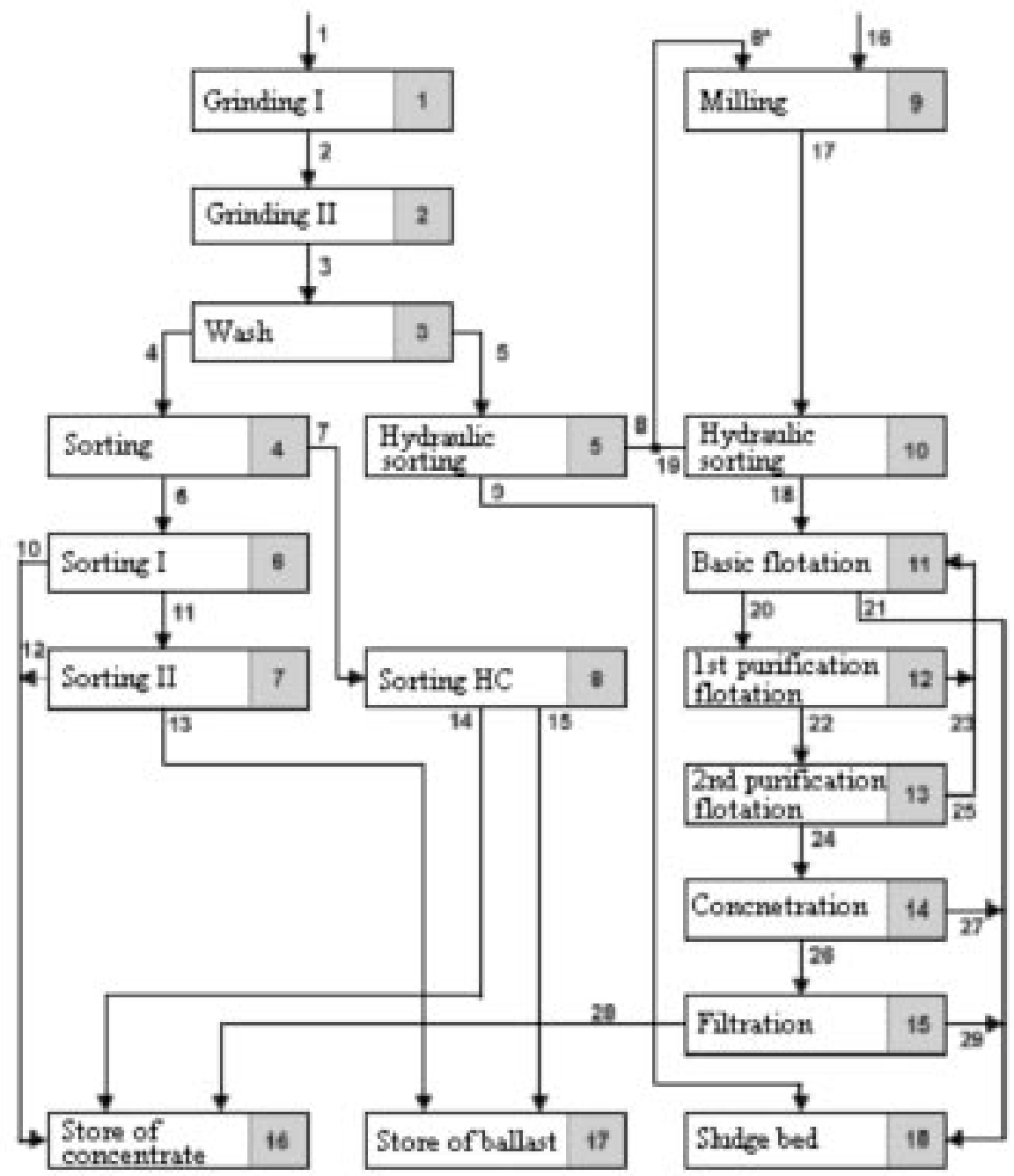

Fig. 2. Technological scheme of processing of magnesite raw material

in the system, the listed vector can also be multidimensional. For simpler calculation it is useful to express the amount of particular components, e.g. fractions, fractions of different density etc. by weight of these components, $k=1,2, \ldots, K$-number of studied components.

Vector $\boldsymbol{Q}_{0}$ - presents the input - batch to the finishing plant.

In general the vector $\boldsymbol{Q}_{i}$ can be expressed:

$$
\sum_{k=1}^{K} q_{i k}=Q_{i}
$$

where $q_{i k}$ are the elements of the vector.

The elements can be calculated from the expression

$$
q_{i k}=\beta_{i k} \bullet Q_{i}
$$

where $\beta_{i k}$ expresses the amount of the $k$ fraction in the material flux $i$ [weight fraction]. If it is possible to determine the granular structure by certain type of distribution (normal, lognormal, Weibull, exponential etc.) or certain distribution function, the content of particular fractions can be calculated from corresponding functions and it is enough to set just the parameters of these functions. Batch to the mill from the point of granularity has various compositions. If the material is grinded in the $1^{\text {st }}$ and $2^{\text {nd }}$ stage, the granularity of the material fluxes changes - thus the amount of fractions decisive for technology is changing. They are the fractions $0-(3) 5 \mathrm{~mm},(3) 5-12(15) \mathrm{mm},(12) 15-$ $40(60) \mathrm{mm}$ that are in given order to be modified by flotation (operations 11,12,13), sorting in dynamic 
Preparatory modification operations:

$$
\begin{array}{rlll}
\mathbf{Q}_{1} & = & \mathbf{Q}_{0} & \mathbf{1} \\
\mathrm{DR}_{1} \cdot \mathrm{Q}_{1}-\mathrm{Q}_{2} & = & 0 & \mathbf{2} \\
\mathrm{DR}_{2} \cdot \mathrm{Q}_{2}-\mathrm{Q}_{3} & = & 0 & \mathbf{3} \\
\mathrm{PM}_{3} \cdot \mathrm{Q}_{3}-\mathrm{Q}_{4} & = & 0 & \mathbf{4} \\
\mathrm{Q}_{3}-\mathrm{Q}_{4}-\mathrm{Q}_{5} & = & 0 & \mathbf{5} \\
\mathrm{TR}_{4} \cdot \mathrm{Q}_{4}-\mathrm{Q}_{6} & = & 0 & \mathbf{6} \\
\mathrm{Q}_{4}-\mathrm{Q}_{6}-\mathrm{Q}_{7} & = & 0 & \mathbf{7} \\
\mathrm{TR}_{5} \cdot \mathrm{Q}_{5}-\mathrm{Q}_{8} & =0 & \mathbf{8} \\
\mathrm{Q}_{5}-\mathrm{Q}_{8}-\mathrm{Q}_{9} & =0 & \mathbf{9}
\end{array}
$$

Gravitation sorting:

$$
\begin{aligned}
& \mathrm{RM}_{6} \cdot \mathrm{Q}_{6}-\mathrm{Q}_{10}=0 \quad \mathbf{1 0} \\
& \mathrm{Q}_{6}-\mathrm{Q}_{10}-\mathrm{Q}_{11}=0 \quad \mathbf{1 1} \\
& \mathrm{RM}_{7} \cdot \mathrm{Q}_{11}-\mathrm{Q}_{12}=0 \quad \mathbf{1 2} \\
& \mathrm{Q}_{11}-\mathrm{Q}_{12}-\mathrm{Q}_{13}=0 \quad \mathbf{1 3} \\
& \mathrm{RM}_{8} \cdot \mathrm{Q}_{7}-\mathrm{Q}_{14}=0 \quad \mathbf{1 4} \\
& \mathrm{Q}_{7}-\mathrm{Q}_{14}-\mathrm{Q}_{15}=0 \quad \mathbf{1 5}
\end{aligned}
$$

conditions (operation 8) and static conditions (operations 6,7 ). If the batch is variable and it is grinded in existing grinders - operations 1 and 2, if we have different efficiency of wash and sorting - operations 3 , 4,5 , portion of these fractions is different. Changeability of composition can be found out by simulation using mathematical model of preparatory operations, equations ( 1 to 9 ) from file 1.

\section{Operators:}

$\mathbf{D R}_{\mathbf{j}}$ - operator of grinding in operation $j$, represents the principles of disintegration of existing and of formation of new fractions. Operator of grinding $\mathbf{D R}$ is represented as follows

$$
D_{\mathbf{j}}=\mathbf{B}_{\mathbf{j}} \cdot \mathbf{S}_{\mathbf{j}}+\mathbf{E}-\mathbf{S}_{\mathbf{j}}
$$

The matrix $\mathbf{B}_{\mathbf{j}}$ presents disintegration (columns) and formation (rows) of fractions. It is a triangular matrix

\section{Flotation sorting :}

Milling :

$$
\begin{array}{rlll}
\mathrm{Q}_{8}+\mathrm{Q}_{8}^{*}+\mathrm{Q}_{19}-\mathrm{Q}_{16} & = & 0 & \mathbf{1 6} \\
\mathrm{GM}_{9} \cdot \mathrm{Q}_{16}-\mathrm{Q}_{17} & = & 0 & \mathbf{1 7} \\
\mathrm{TR}_{10} \cdot \mathrm{Q}_{17}-\mathrm{Q}_{18} & = & 0 & \mathbf{1 8} \\
\mathrm{Q}_{17}-\mathrm{Q}_{18}-\mathrm{Q}_{19} & = & 0 & \mathbf{1 9}
\end{array}
$$

$$
\begin{array}{rlll}
\multicolumn{5}{c}{\text { Flotation: }} \\
\mathrm{RMF}_{11} \cdot \mathrm{Q}_{18}-\mathrm{Q}_{20}= & 0 & \mathbf{2 0} \\
\mathrm{Q}_{18}-\mathrm{Q}_{20}-\mathrm{Q}_{21}+\mathrm{Q}_{23}+\mathrm{Q}_{25}= & 0 & \mathbf{2 1} \\
\mathrm{RMF}_{12} \cdot \mathrm{Q}_{20}-\mathrm{Q}_{22}= & 0 & \mathbf{2 2} \\
\mathrm{Q}_{20}-\mathrm{Q}_{22}-\mathrm{Q}_{23} & = & 0 & \mathbf{2 3} \\
\mathrm{RMF}_{13} \cdot \mathrm{Q}_{22}-\mathrm{Q}_{24}= & 0 & \mathbf{2 4} \\
\mathrm{Q}_{22}-\mathrm{Q}_{24}-\mathrm{Q}_{25} & = & 0 & \mathbf{2 5} \\
& & & \\
\text { Complementary processes: } & \\
\mathrm{OZ}_{14} \cdot \mathrm{Q}_{24}-\mathrm{Q}_{26} & = & 0 & \mathbf{2 6} \\
\mathrm{Q}_{24}-\mathrm{Q}_{26}-\mathrm{Q}_{27} & = & 0 & \mathbf{2 7} \\
\mathrm{OF}_{15} \cdot \mathrm{Q}_{26}-\mathrm{Q}_{28} & = & 0 & \mathbf{2 8} \\
\mathrm{Q}_{26}-\mathrm{Q}_{28}-\mathrm{Q}_{29} & = & 0 & \mathbf{2 9}
\end{array}
$$

format $(K \mathrm{x} K)$, its elements are determined by the standard characteristics of the grinder.

The matrix $\mathbf{S}_{\mathbf{j}}(K \times K)$ presents the conditions of grinding in gap in operation $j$.

$\mathbf{E}$ is a unit matrix with same format $(K x K)$.

The models of grinding and milling in further technological operations are formed similarly (Leško 1998). Values of elements of matrix B and $S$ are given by the results of measurement.

$\mathbf{P M}_{\mathrm{j}}$ - operator of wash represents the distribution of solid state in consequence of wash. It is a diagonal matrix format $(K \mathrm{x} K)$. Operator $\left(\mathbf{E}-\mathbf{P} \mathbf{M}_{\mathbf{j}}\right)$ - represents the transition of solid state to sludge.

$\mathbf{T R}_{\mathbf{j}}$ - operator of sorting represents the distribution of fractions to sifting products. It is a diagonal matrix format $(K \mathrm{x} K)$. The element on the main diagonal $t r_{i i}$ 
represents the distribution of fraction to sifting product. For sorting on sieves and grate is valid the condition that grains with diameter $d<d_{R}$ pass to the sifting product in certain proportion depending on effectiveness of sorting $\eta_{r}<1$. Grains $d<d_{R}$ do not get to the sifting product $t r_{i j}=0 . d_{R}$ splitting granularity - mesh of sieve, aperture of grate etc. For hydraulic separation splitting granularity $d_{R}$ is determined by the separation characteristic of the separator and generally it is valid that $t r_{i j}<1$.

Hydraulic separation in a helix separator in operation 5 indeed serves to sludge the aluminous addition that loses validity because of transition to underground mining. In this operation $1-2 \%$ of material can be lost in the form of sludge.

Values of elements of $\mathbf{T} \mathbf{R}_{\mathrm{j}}$ are determined by experimental measurements.

$\mathbf{R M}_{\mathbf{j}}$ - operator characterizing the distribution of studied fractions to particular products of sorting $(K \mathrm{x} K)$ Operators $\mathrm{RM}_{6}$ and $\mathrm{RM}_{7}$ have similar forms and the elements on the main diagonal determine the transition of particular fraction to the concentrate I. (10) or II. (12).

The distribution function of operation is often represented in a analytical form by approximating functions - e.g. distribution function of normal or lognormal distribution. Tichonov (1978) recommends approximating by hyperbolic tangent, where the arguments of functions are decisive parameters of distribution.

$\mathbf{G M}_{\mathbf{j}}$ - Operator characterizing the milling of raw material and like the operator of grinding it presents the principle of disintegration and formation of new fractions, matrix format $(K \times K)$ (Šotek et al. 1986).

If the act of milling in the milling cycle $i$ is presented by the matrix $\mathbf{M L}_{\mathrm{i}}$, the operator $\mathbf{G M}_{10}$ by Lynch (1981) for $\mathrm{N}$ cycles of milling is in the form of

$$
\mathbf{G M}_{\mathbf{1 0}}=\prod_{i=1}^{N} \mathbf{M L}_{\mathbf{1 0}}
$$

The milling cycle by this meaning is connected with certain effectiveness of the apparatus. For ball mills there can be a certain time interval during which the grain remains in a certain zone of milling. Assuming the milling runs under the same conditions in same zones it is in the form of

$$
\mathbf{G M}_{10}=\mathbf{M L}^{N} .
$$

It is necessary to determine the characteristic of mill ML and the parameter $\mathrm{N}$ experimentally.

$\mathbf{R M F}_{\mathbf{j}}$ - operator characterizing the distribution of flotation fractions in operation $j$ to particular products. It is represented by diagonal matrix format $(K \mathrm{x} K)$ (Leško 1998).

Experimental determination of elements of this operator is very complicated, for this reason it is often substituted with method shortly described below and it is theoretically elaborated in literature (Leško 1998; Tichonov 1978). As the mathematical model in mentioned interpretation (Tichonov 1978) is complicated for obtaining the elementary information on batch, in this phase a mathematical model of flotation that comes out of the theory of flow graphs (Leško 1998) can be used. According to this, fluxes inside the system can be calculated if the flux surrounding the system is known, in this case, feed to the basic operation $\mathrm{Q}_{\mathrm{x}}\left(\mathrm{Q}_{18}\right)$ and the distribution operator of flotation according to relation

$$
\left(\mathbf{R M F}_{\mathbf{j}}^{T}\right)^{-1} \bullet \mathbf{Q}_{x}=\mathbf{Q}_{y}
$$

vector $\mathbf{Q}_{\mathrm{y}}$ represents the feed to the system.

Operator $\mathbf{R M F}^{\mathrm{T}}$ - represents the distribution of mass and particular components in the studied system and its elements represent the distribution of mass of the studied components, e.g. $\mathrm{SiO}_{2}, \mathrm{CaO}$ in particular separating operations. The matrix MRT in transposed form is given by the matrix conjunction

$$
\mathbf{M R F}^{T}=\mathbf{M}^{T} \bullet \mathbf{R} \mathbf{T}^{T}
$$

where the matrix:

$\mathbf{M}$ - is coincident matrix of the system and determines the system structure,

$\mathbf{R F}$ - is the matrix of boundary operators and presents the technological aspects of flotation distribution,

$\mathbf{O Z}$ - operator of thickening characterizing the process of thickening by diagonal matrix, the elements of the diagonal matrix represent transition of solid state to thickened product,

$\mathbf{O F}$ - operator of filtration that in the form of diagonal matrix presents transition of solid state to dewatered product - filter cake.

Dimension of operators OZ and OF depends on the chosen rate of these processes.

The suggested mathematical model of modification of magnesite raw material can become the elementary 
- universal model suitable for evaluation of processes of modification of magnesite raw material for any arbitrary system under these conditions:

1. The system of equations transformed to the form

$$
\text { MS } \bullet Q=Q_{0}
$$

where MS is the system matrix composed of sub matrixes $\mathrm{SMS}_{\mathrm{ij}}$. The format of matrix MS is $(j \mathrm{xj})$, where $j$ is the number of technological operations in the studied system. The format of sub matrixes is $(K x K)$.

Sub matrix $\mathrm{SMS}_{\mathrm{ij}}$ in the system matrix is clearly defined by the indexes:

- number of raw, it is given by the serial number of vector equation - index $i$,

- number of column gives the serial number of vector in the appropriate vector equation - index $j$.

The sub matrixes representing the corresponding material fluxes are diagonal unit matrixes

$$
S M S_{i j}=\operatorname{diag}(1,1, \ldots, 1)
$$

format $(K x K)$

2. The matrix MS should be understood by the way it is composed in conjunction of structural - coincidental matrix M and matrix of boundary - nodal operators R. This representation of the system creates conditions for formalization of problem that is based on separation of structural and technological matter. Formalization of the problem enables:

- to select the arbitrary structure of the system,

- to assign entered characteristics to particular elements of the system according to a selected structure.

The presented fact will have a positive effect:

- for solving it is not necessary to transcribe vector equations of type (1) to linear equations,

- variation of structure of the technological scheme as well as variations of particular operators can be realized according to certain selected principles, where a wide range of possible system conditions can be created that enables to analyse the conduct of system in wider scale.
The elemental factor that must be determined during realization of the whole model is:

- whether the raw material in the technological cycle will be studied from the point of fractions when flowing through the whole system

- or it will be so only in those cycles of modification, where particular characteristic is relevant.

In the first case the model is complicated by formation of multidimensional files and more elementary information on the raw material are needed.

The second case, i.e. solving of the problem by particular operations, is more feasible because with the existing equipment the first way is difficultly realizable.

The facts mentioned above must be considered in a adequate program of processing.

Concentrates from the store - operation 16 - are transported to thermal processing according to its quality.

\section{Mathematical model of production and modification of magnesite sinters}

Thermal processing is concentrated to

- production of magnesite sinters,

- modification of magnesite sinters

and it is shown in Fig.1. The development of technological scheme of thermal processing is not realized for vastness of material and that is also why a mathematic equivalent is not introduced.

A mathematical model of modification of magnesite sinters can be described similarly as modification of raw material. It depends only on the form of used mathematical models of particular operations.

Mathematical models in general enables studying particular dosage of concentrates from the moment of creation to final modification into magnesite sinter of certain granularity and quality.

The results of analysis of the technological system of modification of magnesite raw material and sinter enable simulation of technological process of modification and production of sinters according to particular types by suggested mathematical model and if technological aspects are integrated they enable optimizing the whole technological process. 


\section{Requirements to preparation and possibilities of use of mathematical model of magnesite modification}

It is necessary to realize analysis of technological elements of modification system to prepare the presented model. It is necessary to do the analysis so that the following questions are answered:

a) Does recorded data that would enable evaluation of performance of technological operations in the past period exist?

b) Does the existing data enable to express mathematical characteristic of technological operations?

c) Which elementary data are necessary to record and register so that it is possible to fulfil the problem defined in point b) and improve the created mathematical model?

d) Can the characteristic of particular operation be determined with satisfactory precision by one or more measurements?

e) Which elementary data, except for already studied, are necessary to measure and record in the operation systematically?

The requirements listed above are taken into consideration in following part.

Mathematical models of grinding, milling and sorting are used in calculation in the way they are listed in previous text.

Following characteristics of operation, batch and conditions of modification were used in calculation:

\section{Batch}

Fractions

\begin{tabular}{|l|c|c|c|c|c|}
\hline Fraction [mm] & $0-25$ & $25-50$ & $50-100$ & $100-300$ & $300-500$ \\
\hline Weight yield [\%] & 10 & 15 & 20 & 35 & 20 \\
\hline Damp [\%] & \multicolumn{5}{|c|}{1.0} \\
\hline Fine-grained dash [\%] & \multicolumn{5}{|c|}{} \\
\hline
\end{tabular}

Fractions after stage II grinding

\begin{tabular}{|c|c|c|c|c|c|c|}
\hline \multirow{2}{*}{$\begin{array}{c}\text { Density } \\
{\left[10^{-3} \mathrm{kg.m} \mathrm{m}^{-3}\right]}\end{array}$} & \multicolumn{3}{|c|}{ Fraction $60-12 \mathrm{~mm}$} & \multicolumn{3}{c|}{ Fraction $12-3 \mathrm{~mm}$} \\
\cline { 2 - 7 } & $\gamma_{i}$ & $\begin{array}{c}\lambda_{\mathrm{s} i} \\
{[\%]}\end{array}$ & $\begin{array}{c}\lambda_{\mathrm{c} i} \\
{[\%]}\end{array}$ & $\begin{array}{c}\gamma_{i} \\
{[\%]}\end{array}$ & $\begin{array}{c}\lambda_{\mathrm{s} i} \\
{[\%]}\end{array}$ & $\begin{array}{c}\lambda_{\mathrm{c} i} \\
{[\%]}\end{array}$ \\
\hline+3.00 & 11.2 & 0.64 & 0.45 & 19.2 & 0.36 & 0.30 \\
\hline $2.98-3.00$ & 21.4 & 0.82 & 0.62 & 20.1 & 0.75 & 0.60 \\
\hline $2.96-2.98$ & 36.3 & 1.46 & 0.96 & 12.8 & 1.72 & 1.10 \\
\hline $2.94-2.96$ & 13.6 & 2.86 & 2.50 & 15.8 & 3.02 & 1.75 \\
\hline-2.94 & 17.5 & 10.56 & 6.30 & 30.1 & 9.50 & 6.50 \\
\hline
\end{tabular}

$\gamma_{i}$ - weight yield

$\lambda_{\mathrm{S} i}-$ content of $\mathrm{SiO}_{2}$ in fraction $i$

$\lambda_{\mathrm{c} i}-$ content of $\mathrm{CaO}$ in fraction $i$ 


\section{Sorting}

Operation 3:

Fraction $-0.5 \mathrm{~mm}$ and present fine-grained material is washed up from washing barrel to the helix sorter.

Operation 4:

Mesh of sieve $\mathrm{a}=\mathrm{d}_{\mathrm{R}}=12 \mathrm{~mm}$ :

\begin{tabular}{|l|c|c|c|c|}
\hline Fraction [mm] & $0-3$ & $3-10$ & $10-12$ & +12 \\
\hline Distribution characteristic & 1.0 & 0.95 & 0 & 0 \\
\hline
\end{tabular}

Operation 5:

Distribution characteristic is given parametrically; it is supposed to be described by normal distribution function with parameters

$\mathrm{d}_{\mathrm{R}}=0.05 \mathrm{~mm}, \mathrm{~S}_{\mathrm{d}}=0,012 \mathrm{~mm}$.

\section{Grinding and milling}

Characteristics of the grinders are given numerically:

Operation 1:

\begin{tabular}{|l|c|c|c|c|c|}
\hline Fraction [mm] & +150 & $150-100$ & $100-50$ & $50-25$ & $25-0$ \\
\hline Weight yield [\%] & 15 & 24 & 30 & 14 & 17 \\
\hline
\end{tabular}

Operation 2:

\begin{tabular}{|l|c|c|c|c|c|}
\hline Fraction [mm] & +60 & $60-30$ & $30-12$ & $12-3$ & $3-0$ \\
\hline Weight yield [\%] & 12 & 37 & 25 & 18 & 8 \\
\hline
\end{tabular}

Operations 9, 10:

Milling is not presented in this paper. 


\section{Sorting}

Operations 6 and 7: dense suspensions.

\begin{tabular}{|l|c|c|c|c|c|}
\hline Number of fraction & 1 & 2 & 3 & 4 & 5 \\
\hline Distribution characteristic I & 1.0 & 0.925 & 0.589 & 0.439 & 0 \\
\hline
\end{tabular}

Operation 8: dense suspension cyclone.

\begin{tabular}{|l|c|c|c|c|c|}
\hline Number of fraction & 1 & 2 & 3 & 4 & 5 \\
\hline Distribution characteristic II & 1.0 & 0.98 & 0.85 & 0.22 & 0 \\
\hline
\end{tabular}

Losses on finished products are negligibly small in unwatering. In calculations it is supposed that the material is not accumulated in holding bins, only one qualitative category of batch is considered and no variations. In case of need the model can be used for various working conditions.

The results of calculation according to Fig. 2 are presented in Table 1.

Table 1 Results of calculation

\begin{tabular}{|c|c|c|c|c|}
\hline $\begin{array}{l}\text { Number } \\
\text { of prod. }\end{array}$ & Term & $\begin{array}{c}\gamma_{i} \\
{[\%]}\end{array}$ & $\begin{array}{l}\lambda \mathrm{S} i \\
{[\%]}\end{array}$ & $\begin{array}{l}\lambda_{\mathrm{C} i} \\
{[\%]}\end{array}$ \\
\hline \multicolumn{2}{|c|}{ Batch $0-500$} & \multicolumn{3}{|l|}{100} \\
\hline \multirow{2}{*}{1} & water & 6.5 & & \\
\hline & batch & 93.5 & 3.81 & 2.46 \\
\hline \multicolumn{2}{|c|}{ Concentrates } & \multicolumn{3}{|l|}{57.39} \\
\hline 10 & concentrate I & 22.37 & 1.23 & 0.90 \\
\hline 12 & concentrate II & 8.37 & 1.65 & 1.49 \\
\hline 14 & concentrate $\mathrm{HC}$ & 14.85 & 0.97 & 0.68 \\
\hline 24 & flotation concentrate & 11.80 & 0.60 & 0.60 \\
\hline \multicolumn{5}{|c|}{ Wastes 36.11} \\
\hline 13 & waste from static & 7.60 & 9.28 & 5.65 \\
\hline 15 & waste from $\mathrm{HC}$ line & 12.62 & 7.17 & 4.80 \\
\hline 21 & waste from flotation & 14.09 & 8.65 & 5.10 \\
\hline 9 & sludge & 1.80 & & \\
\hline
\end{tabular}

$\gamma_{i}$ - weight yield

$\lambda_{\mathrm{S} i}-$ content of $\mathrm{SiO}_{2}$ in fraction $i$

$\lambda_{\mathrm{C} i}-$ content of $\mathrm{CaO}$ in fraction $i$ 


\section{Conclusion}

From the knowledge obtained during model production arises that for increase of efficiency of processing of magnesite raw material as well as for effective assessment of deposits is generally necessary:

- to join directly the exploration of deposit with technological research so that the output product was information on technological types of raw material,

- to organize mining and processing of raw material according to technological types with the assuring of information fluxes from mining to finished product.

If economical data are added, the model can provide complex information on possible economical results of processing of appropriate raw material.

\section{References}

Jarco, P. \& Skála, K. 1986: Vývoj flotaèní úpravy slovenských magnezitù, Rudy è. 7, , pp 183-186.

Leško, M. \& Zeleňák, F. 1994: Matematický model úpravy magnezitu, Zb.: 11 th International Conference on Process Control and Simulation, Košice, pp 190-196.

Leško, M. 1996: Matematické modely zdrobňovacích strojov a ich využitie pri tvorbe technologických schém drvenia. Zb. 12 th Int. Conference on Process Control and Simulation, ASRTP '96, II. diel, pp 6-15.
Leško, M. 1998: Maticové modely technologických systémov, F BERG Košice.

Lynch, A. J. 1981: Cykly droblenija i izmelčenija, Nedra Moskva.

Šotek, O., Sehnálek, F. \& TOPORČ ÁK, Š. 1986: Technologické a výrobkové inovácie v magnezitovom priemysle v n.p. SMZ, Rudy č. 7, 1986, pp 197-201.

Tichonov, O. N. 1978: Teoretičeskije osnovy separacionnych procesov obogaščenija poleznych iskopajemych. Uč. posilije, Leningrad. 